\title{
ASPECTOS DE RELIGIOSIDADE NA SAÚDE VOCAL DE CANTORES DE GRUPOS DE LOUVOR
}

\section{Aspects of religiousness in the vocal health of worship group singers}

\author{
Regina Zanella Penteado (1), Cibelle Brito da Silva ${ }^{(2)}$, Priscila Fabiana Agostinho Pereira ${ }^{(3)}$
}

\section{RESUMO}

Objetivo: identificar, em participantes de Grupo de Louvor, aspectos de religiosidade presentes no saber e nas práticas relacionadas ao uso da voz e aos cuidados de saúde vocal. Métodos: pesquisa qualitativa, que envolve dados de desenho e depoimento escrito sobre a voz, questionário aberto e grupo focal, categorizados a partir da análise de conteúdo/análise temática. Resultados: são apresentados a partir das categorias e atributos: sócio-cultural (relação com as pessoas e com Deus), componente essencial, evangelização, profissional, saúde vocal e parâmetros vocais. Conclusão: foram evidenciadas a valoração e a importância da voz para se relacionar com Deus e para realizar as práticas religiosas e as atividades de evangelização, além da prevalência de crenças religiosas e da oração dentre as práticas de cuidados com a voz/saúde vocal e geral. A pesquisa evidenciou necessidades, saberes e práticas relacionadas aos usos da voz e saúde vocal e afirma a relação entre saúde e espiritualidade/religiosidade, mostrando que tal relação é importante e não pode ser negligenciada pelos fonoaudiólogos que se propõem a trabalhar na promoção da saúde vocal de cantores evangélicos.

DESCRITORES: Voz; Religião; Promoção da Saúde; Cultura

\section{INTRODUÇÃO}

O uso da voz no exercício religioso demanda flexibilidade e saúde vocal para responder às necessidades e condições de produção vocal, de expressividade e de ajustes vocais e corporais ${ }^{1-3}$ condizentes aos diferentes propósitos, contextos, locais e condições de produção.

No meio evangélico, o Grupo de Louvor é uma das funções e manifestações mais importantes da voz cantada nas programações da igreja. Trata-se de um serviço composto por fiéis que têm interesse pela música e pelo canto, sendo eles cantores (leigos e/ou profissionais da voz) e músicos (baterista, tecladista, guitarrista, baixista, violonista, percussio-

(1) Fonoaudióloga; Docente do Curso de Fonoaudiologia da Universidade Metodista de Piracicaba; Mestre e Doutora em Saúde Pública pela Faculdade de Saúde Pública da Universidade de São Paulo.

(2) Fonoaudióloga.

(3) Fonoaudióloga da Clínica Pirâmide Pró-Saúde e Coordenadora do Grupo de Louvor da Igreja Metodista da Vila Joaquim Inácio em Campinas - SP. nista, instrumentistas de sopro), bem como técnicos de som e vídeo. O Grupo de Louvor tem a importante função de dirigir a comunidade para a prática do canto durante a realização do culto, com a tarefa de conduzir os fiéis a louvar e a adorar a Deus.

Estudos ${ }^{4-7}$ realizados com cantores de igreja católica e cantores de Grupos de Louvor de igreja evangélica evidenciaram que a maioria não conta com formação ou preparo vocal adequado nem com orientação, assessoria ou acompanhamento fonoaudiológico e que muitos sujeitos apresentam queixas em relação à voz cantada: dificuldades para atingir tons, cansaço vocal, dificuldade em manter a frase musical, rouquidão, "ar" na voz, dificuldade na respiração, pigarro, dor e ardor ao cantar, lembrando que tais queixas podem estar relacionadas a disfunções e alterações vocais.

As pesquisas mostram, ainda, que os cantores de Grupo de Louvor possuem pouco conhecimento sobre o uso da voz; que o fazem de maneira inadequada e abusiva; que possuem algum conhecimento de higiene vocal, embora freqüentemente apresentem hábitos inadequados e realizem comportamentos prejudiciais à saúde vocal, deixando 
de realizar hábitos que poderiam melhorar a voz ${ }^{4-7}$. Por outro lado, sabe-se que a prática do canto em igrejas evangélicas também pode promover 0 aumento da extensão vocal e amenizar os efeitos do envelhecimento vocal ${ }^{8}$.

As pessoas percebem, representam e lidam com o seu processo saúde-doença-cuidado a partir dos conhecimentos, experiências, crenças, cultura, historicidade e qualidade de vida ${ }^{9,10}$. Assim, as questões de religiosidade e espiritualidade são importantes para a avaliação em saúde e compreensão dos modos de lidar com o processo saúde-doençacuidado ${ }^{11-15}$, já que são geradoras de conforto e referenciais auxiliares na busca do bem estar, da saúde, da segurança, da força, da dignidade, do significado e da construção de sentidos para a vida humana - principalmente a partir de três componentes: a necessidade de encontrar significado, a necessidade de ter esperança e vontade para viver e a necessidade de ter fé em si, nos outros e em Deus.

Além disso, as questões de religiosidade e espiritualidade integram a cultura de uma sociedade e/ou comunidade, que deve ser considerada nos processos educativos para a promoção da saúde 16-25. Entende-se, assim, que a discussão acerca da espiritualidade deveria fazer parte da formação dos profissionais da saúde e da reorientação das suas práticas profissionais ${ }^{15}$.

Ressalta-se, neste trabalho, a importância de se conhecer os significados atribuídos à voz, as maneiras como os sujeitos usam a voz e cuidam da sua saúde no meio religioso, bem como de se compreender de que forma a religiosidade e as crenças a ela relacionadas interferem nos usos e cuidados com a voz e a saúde vocal.

A presente pesquisa focaliza cantores de Grupos de Louvor de Igreja Evangélica com o objetivo de identificar aspectos de religiosidade nas representações, saberes e práticas relacionadas ao uso da voz e aos cuidados de saúde vocal. O estudo visa contribuir com subsídios para a atuação da Fonoaudiologia junto a comunidades religiosas.

\section{MÉTODOS}

Foram sujeitos da pesquisa nove integrantes do Grupo de Louvor de uma Igreja do Evangelho Quadrangular da cidade de Piracicaba (SP), sendo seis mulheres e três homens.

A pesquisa, de caráter qualitativo, envolve diferentes fontes de dados: registros de desenho e depoimento escrito sobre a voz, questionário com perguntas abertas e grupo focal.

A realização de desenho e depoimento escrito sobre a voz foi solicitada a partir da questão: "O que você acha da própria voz e como vê a sua voz no meio religioso?". Vale destacar que, na presente pesquisa, o interesse pelo desenho não está na exatidão de suas formas, mas sim enquanto sistema de representação simbólica e possibilidades de objetivação de sentimentos, pensamentos, conhecimentos, significações, de projeção do esquema corporal e da própria imagem (vocal) refletida no papel e de expressão da subjetividade e da cultura ${ }^{26-30}$.

O questionário (Figura 1) com perguntas abertas englobou aspectos relacionados ao valor e/ou importância da voz; aos sentidos na voz no meio

\section{Questionário}

Data: ________ Igreja:

Nome: (Iniciais) Sexo: Idade:

Tempo de ministério:

1 - Qual é o valor e/ou importância da sua voz?

2 - Para que serve e quais os sentidos da voz no meio religioso? E no Grupo de Louvor?

3 - Você acha que a sua fé influencia na sua voz? Explique.

4 - Você acha que o fato de cantar no grupo de louvor interfere ou modifica a sua voz? Quais mudanças? Na sua opinião, por quê ocorrem e de que decorrem as mudanças?

5 - Se, após cantar no grupo de louvor, você perceber sua voz rouca, cansada ou algum desconforto vocal, qual significado isso tem para você?

6 - Você tem alguma queixa, dificuldade ou problema com a voz? Qual?

7 - Quais os cuidados e as coisas que você faz para melhorar a sua voz? (inclusive no campo da religiosidade). 
religioso e no Grupo de Louvor; às interferências da fé e da prática de canto no grupo de louvor na voz; às queixas, dificuldades ou problemas vocais; e aos cuidados com a voz e saúde vocal.

Foi realizado um grupo focal, uma técnica de pesquisa qualitativa que utiliza sessões grupais como facilitadoras da expressão de características psicossociológicas, culturais e de práticas cotidianas. Trata-se de uma espécie de entrevista coletiva pouco estruturada, conduzida por um moderador e orientada por algumas questões pré-elaboradas desenvolvidas pelos participantes em forma de discussões e conversas, de maneira que todos possam participar de forma descontraída e trocar experiências em um ambiente agradável, convidativo, informal, motivador e não constrangedor ${ }^{31}$. As questões que orientaram as discussões do grupo focal visavam o esclarecimento acerca de aspectos como os usos da voz na relação com Deus e no trabalho de evangelização e do uso de orações em prol da voz/saúde vocal.

A pesquisa foi aprovada pelo CEP/UNIMEP (Protocolo $19 / 06,29 / 03 / 06$ ) e os sujeitos leram e assinaram o Termo de Consentimento Livre e Esclarecido conforme resolução MS/CNS/CNEP nำ 196/96 de 10/10/1996.

Foi realizada a análise de conteúdo/análise temática dos desenhos, depoimentos, questionário e transcrições do grupo focal, procurando-se identificar categorias e conjuntos temáticos.

\section{RESULTADOS}

A partir da análise dos dados dos desenhos, depoimentos, questionários e grupo focal foram identificadas categorias e conjuntos temáticos referentes a alguns atributos e parâmetros vocais, apresentados nas Figuras de 2 a 8.

A Figura 2 apresenta a distribuição dos resultados referentes ao atributo Sócio-Cultural /Relação com as pessoas.

A Figura 3 apresenta os resultados referentes ao atributo Sócio-Cultural / Relação com Deus, conforme as diferentes modalidades e intenções de tal relação, ou seja: comunicação (quando se pressupõe uma relação de "duas vias" entre o sujeito e Deus); invocação (quando se trata de um pedido ou clamor, do sujeito para Deus - uma via) e louvor/adoração (do sujeito em relação a Deus - uma via).

A Figura 4 apresenta os resultados referentes ao atributo Componente Essencial.

A Figura 5 apresenta os resultados referentes ao atributo Evangelização (contextos de pregação e/ou propagação do evangelho).

A Figura 6 apresenta os resultados referentes ao atributo Profissional.

A Figura 7 apresenta os resultados referentes ao atributo Saúde Vocal.

A Figura 8 apresenta os resultados de desenhos e depoimentos escritos sobre a voz conforme os parâmetros vocais de qualidade vocal, loudness $e$ pitch.

\begin{tabular}{|c|c|c|c|}
\hline \multicolumn{4}{|c|}{ ATRIBUTO SÓCIO-CULTURAL - relação com as pessoas } \\
\hline $\mathbf{S}$ & Desenho & Depoimento & Questionário \\
\hline 1 & $\begin{array}{c}2 \text { bocas, } 2 \text { riscos em aspiral } \\
\text { (um amarelo e um marrom) } \\
\text { e notas musicais }\end{array}$ & - & $\begin{array}{l}\text { tanto para minha comunicação } \\
\text { como para meu trabalho }\end{array}$ \\
\hline 2 & $\begin{array}{l}\text { lua, estrela, nuvem, sol, } \\
\text { homem, notas musicais }\end{array}$ & $\begin{array}{c}\text { uso minha voz para me } \\
\text { expressar e comunicar, seja } \\
\text { com Deus ou com os } \\
\text { homens }\end{array}$ & com a minha voz eu consigo me comunicar \\
\hline 3 & $\begin{array}{c}\text { boca, risco, clave de sol } \\
\text { (escreveu: "blá-blá" e "lá-lá") }\end{array}$ & - & $\begin{array}{l}\text { é um dos meios mais importantes para a } \\
\text { comunicação }\end{array}$ \\
\hline 4 & - & através dela eu canto, falo. & através da voz você se comunica com as pessoas \\
\hline 5 & - & - & com ela nos comunicamos \\
\hline 6 & - & - & $\begin{array}{c}\text { valorizo minha voz fazendo com ela só coisas boas } \\
\text { para mim e para os outros }\end{array}$ \\
\hline 7 & $\begin{array}{c}\text { (escreveu: Bom-Bril/1001 } \\
\text { utilidades) }\end{array}$ & $\begin{array}{l}\text { através da minha voz eu } \\
\text { falo e canto. }\end{array}$ & $\begin{array}{l}\text { a minha voz é importante para eu me comunicar } \\
\text { com as pessoas }\end{array}$ \\
\hline 8 & - & - & é importante para falar \\
\hline 9 & - & - & poder falar e comunicar-se com as pessoas \\
\hline
\end{tabular}

Figura 2 - Distribuição dos resultados na categoria atributo Sócio-Cultural - relação com as pessoas 


\begin{tabular}{|c|c|c|c|c|}
\hline & $\mathbf{S}$ & DEPOIMENTO & QUESTIONÁRIO & GRUPO FOCAL \\
\hline \multirow{3}{*}{ 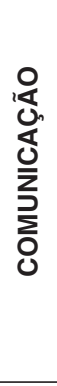 } & 2 & $\begin{array}{l}\text { uso minha voz } \\
\text { para me } \\
\text { expressar e } \\
\text { comunicar com } \\
\text { Deus }\end{array}$ & - & - \\
\hline & 4 & - & - & $\begin{array}{l}\text { posso estar ligada mentalmente } \\
\text { com Deus, conversando com Ele } \\
\text { em meus pensamentos }\end{array}$ \\
\hline & 9 & - & - & $\begin{array}{l}\text { mesmo em silêncio você está } \\
\text { falando com Deus }\end{array}$ \\
\hline \multirow{6}{*}{ 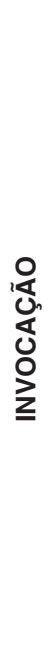 } & 2 & - & $\begin{array}{l}\text { oro a Deus para que me capacite } \\
\text { a louvá-lo e a adorá-lo com a minha voz }\end{array}$ & - \\
\hline & 3 & - & $\begin{array}{c}\text { procuro orar e pedir para que Deus } \\
\text { abençoe e me capacite para o ministério }\end{array}$ & $\begin{array}{l}\text { eu também oro pela minha saúde } \\
\text { em geral, isso faz parte da minha vida }\end{array}$ \\
\hline & 6 & - & - & $\begin{array}{l}\text { a saúde, no geral, é o que a gente } \\
\text { pede para Deus }\end{array}$ \\
\hline & 7 & - & sempre peço a capacitação de Deus & - \\
\hline & 8 & - & sempre oro pela minha voz & - \\
\hline & 9 & - & $\begin{array}{l}\text { oro a Deus para que este mal seja desfeito } \\
\text { e eu tenha a cura e a libertação deste mal }\end{array}$ & - \\
\hline \multirow{6}{*}{ 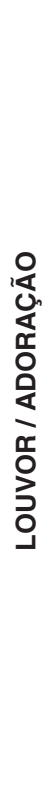 } & 1 & - & $\begin{array}{c}\text { eu uso a minha voz para expressar } \\
\text { o que sinto em relação a Deus, } \\
\text { para adorar a Deus }\end{array}$ & - \\
\hline & 2 & - & $\begin{array}{l}\text { é uma forma de se expressar a Deus, quer } \\
\text { seja em oração (palavras) ou canções } \\
\text { (músicas). No louvor usamos nossa voz } \\
\text { para louvar a Deus por tudo que ele tem } \\
\text { feito por nós e adorá-lo pelo que ele é }\end{array}$ & - \\
\hline & 4 & $\begin{array}{l}\text { através dela eu } \\
\text { expresso o amor } \\
\text { que tenho por Ele }\end{array}$ & louvar e adorar a Deus & $\begin{array}{c}\text { você está naquele momento } \\
\text { de adoração, você começa adorar } \\
\text { a Deus e começa a chorar }\end{array}$ \\
\hline & 7 & - & $\begin{array}{c}\text { a minha voz é importante para louvar } \\
\text { e adorar a Deus }\end{array}$ & - \\
\hline & 8 & - & $\begin{array}{c}\text { é importante para falar, para louvar, } \\
\text { para adorarmos a Deus (...) Expressar } \\
\text { o meu amor a Deus }\end{array}$ & - \\
\hline & 9 & - & poder adorar a Deus com cânticos & $\begin{array}{c}\text { no silêncio você adora a Deus (...) Se } \\
\text { faltar a voz não vai me impedir de adorá-lo }\end{array}$ \\
\hline
\end{tabular}

Figura 3 - Distribuição dos resultados na categoria atributo Sócio-Cultural - relação com Deus 


\begin{tabular}{|c|c|c|c|}
\hline \multicolumn{3}{|c|}{ ATRIBUTO COMPONENTE ESSENCIAL } \\
\hline S & Desenho & Depoimento & Questionário \\
\hline 1 & - & - & o uso da voz pra mim é indispensável \\
\hline 2 & - & - & $\begin{array}{c}\text { a minha voz pra mim } \\
\text { é de extrema importância }\end{array}$ \\
\hline 4 & corações & $\begin{array}{c}\text { sinto uma necessidade extrema } \\
\text { de comunicar, não consigo me ver } \\
\text { de boca fechada }\end{array}$ & a voz é algo de maior valor \\
\hline 5 & - & $\begin{array}{c}\text { através da minha voz eu faço muitas } \\
\text { coisas, por isso que eu digo que tem } \\
\text { muitas utilidades e não dá para viver sem }\end{array}$ & a voz é fundamental \\
\hline 7 & $\begin{array}{c}\text { (escreveu: Bom-Bril } \\
1001 \text { utilidades) }\end{array}$ & \begin{tabular}{l} 
\\
\hline
\end{tabular}
\end{tabular}

Figura 4 - Distribuição dos resultados na categoria atributo Componente Essencial

\begin{tabular}{|c|c|c|}
\hline \multicolumn{3}{|c|}{ ATRIBUTO EVANGELIZAÇÃo } \\
\hline S & Depoimento & Questionário \\
\hline 1 & - & $\begin{array}{c}\text { a voz serve para anunciar a palavra de Deus, } \\
\text { para comunicarmos bênçãos que acontecem }\end{array}$ \\
\hline 3 & - & para falar e ministrar a palavra de Deus \\
\hline 4 & através dela (...) transmito a palavra de Deus & - \\
\hline 5 & - & fazemos os sermões na Igreja \\
\hline 6 & - & uso a minha voz para propagar a palavra de Deus \\
\hline 8 & - & para falar a palavra do Senhor \\
\hline 9 & - & da amor de Deus, transmitindo o plano \\
\end{tabular}

Figura 5 - Distribuição dos resultados na categoria atributo Evangelização (contextos de pregação e/ou propagação do evangelho)

\begin{tabular}{|c|c|c|c|}
\hline \multicolumn{4}{|c|}{ ATRIBUTO PROFISSIONAL } \\
\hline S & Desenho & Depoimento & Questionário \\
\hline \multirow{3}{*}{1} & $\begin{array}{c}\text { 2 bocas, 2 riscos em aspiral } \\
\text { (um amarelo e um marrom) } \\
\text { e notas musicais }\end{array}$ & $\begin{array}{c}\text { no segundo desenho é o uso } \\
\text { no meu trabalho, que eu acho } \\
\text { ser boa e forte }\end{array}$ & $\begin{array}{c}\text { o uso da voz para mim } \\
\text { a minhensável, tanto para } \\
\text { para o meun trabalho }\end{array}$ \\
\hline
\end{tabular}

Figura 6 - Distribuição dos resultados de desenhos, depoimentos e questionário na categoria Atributo Profissional

\section{DISCUSSÃO}

A análise das Figuras 2 e 4 permite notar que os sujeitos afirmam e reconhecem a importância da voz como um componente essencial e de grande valor em suas vidas, com impactos sobre o outro e implicações sociais de comunicação/relação interpessoal, o que é condizente com a vertente fonoaudiológica abordada por autores que consideram a voz na interação social ${ }^{32}$.
$\mathrm{Na}$ literatura fonoaudiológica alguns estudos com religiosos ${ }^{2-7,25}$ evidenciam precárias condições de percepção, conhecimento e importância atribuídas à voz/saúde vocal. $\mathrm{O}$ fato dos sujeitos da pesquisa reconhecerem a importância da voz e a valoração da mesma indica um dado positivo dos conhecimentos e percepções sobre voz do grupo estudado, uma vez que este pode ser um ponto de partida quando se trata dos investimentos em cuidados com a saúde vocal e da busca do aprimoramento vocal com apoio profissional. 


\begin{tabular}{|c|c|c|c|c|}
\hline \multicolumn{5}{|c|}{ ATRIBUTO SAÚDE VOCAL } \\
\hline $\mathbf{S}$ & Desenho & Depoimento & Questionário & Grupo Focal \\
\hline 1 & - & - & $\begin{array}{c}\text { exercícios e tenho feito terapia com } \\
\text { uma fonoaudióloga. }\end{array}$ & - \\
\hline 2 & - & - & $\begin{array}{c}\text { não gritar ou forçar a voz, oro a Deus. } \\
\text { Evito beber gelado e me expor ao } \\
\text { vento e chuva. }\end{array}$ & - \\
\hline 3 & $\begin{array}{c}\text { boca, risco } \\
\text { pontilhado } \\
\text { em palavras, } \\
\text { notas } \\
\text { musicais }\end{array}$ & $\begin{array}{c}\text { às vezes } \\
\text { oscila, quando } \\
\text { acabo por } \\
\text { fazer abuso } \\
\text { vocal (...) na } \\
\text { igreja. }\end{array}$ & $\begin{array}{l}\text { procuro aquecer, desaquecer, fazer } \\
\text { repouso vocal, beber bastante água, } \\
\text { comer maçã antes de atividade vocal. } \\
\text { Procuro orar. }\end{array}$ & $\begin{array}{c}\text { orar e agradecer a Deus pela minha } \\
\text { saúde faz parte do meu estilo de vida. } \\
\text { Eu acho que é importante a oração (...) } \\
\text { Só que, se eu não cuido da minha voz; } \\
\text { se eu não faço nada pra manter uma } \\
\text { boa qualidade vocal; então porque é } \\
\text { que eu vou ficar orando, se eu não } \\
\text { cuido bem da minha voz? } \\
\text { Aquecer a voz, ter o cuidado de } \\
\text { hidratar. }\end{array}$ \\
\hline 4 & - & - & exercícios vocais, oração, fé e ensaios. & $\begin{array}{l}\text { é importante hidratar as pregas vocais; } \\
\text { fazer um aquecimento antes de } \\
\text { começar a ensaiar ou cantar; fazer } \\
\text { desaquecimento e relaxamento. }\end{array}$ \\
\hline 5 & - & - & fazer repouso e boa alimentação. & - \\
\hline 6 & - & - & $\begin{array}{l}\text { procuro seguir orientações técnicas } \\
\text { como aquecimento vocal, boa } \\
\text { alimentação, restrição ao gelado e ser } \\
\text { dependente de Deus. }\end{array}$ & $\begin{array}{c}\text { às vezes eu dou uns gritos lá em casa } \\
\text { (...) a gente sempre faz aquela } \\
\text { competição sonora para falar no } \\
\text { telefone } \\
\text { Peço na oração para que Deus sempre } \\
\text { conserve a saúde. Se o corpo está } \\
\text { doente, automaticamente sua voz vai } \\
\text { ser atingida. } \\
\text { Os meus cuidados normais são: } \\
\text { oração, não tomar gelado, não fazer } \\
\text { competição sonora e a alimentação }\end{array}$ \\
\hline 7 & $\begin{array}{c}\text { Bom-Bril } \\
1001 \\
\text { utilidades }\end{array}$ & eu grito & $\begin{array}{c}\text { nada de treinos e exercícios, apenas } \\
\text { ensaios e sempre peço a capacitação } \\
\text { de Deus. }\end{array}$ & - \\
\hline 8 & - & - & $\begin{array}{l}\text { sempre oro pela minha voz, eu não } \\
\text { bebo muita água gelada, não como } \\
\text { muito banana, estou sempre bebendo } \\
\text { chá com limão e mel, etc. }\end{array}$ & - \\
\hline 9 & - & - & não tomar muito gelado, orar a Deus. & - \\
\hline
\end{tabular}

Figura 7 - Distribuição dos resultados na categoria atributo Saúde Vocal

A análise das Figuras 2, 3 e 6 permite notar, também, que a importância da voz foi melhor percebida nas atividades religiosas e sociais do que nas profissionais. Há diferenças nas maneiras de se perceber a relevância da voz, em função dos seus contextos de uso e situações da vida cotidiana ${ }^{33}$ e os resultados mostram que, para cantores de grupos de louvor, os espaços sociais caracterizados como práticas religiosas são mais significativos para o reconhecimento da importância da voz e as implicações desta na qualidade de vida do que os de práticas profissionais.
A análise das Figuras 3, 4 e 5 permite identificar alguns aspectos de religiosidade que se fazem presentes no saber, na valoração sobre a voz e nas práticas de usos da voz por cantores de grupos de louvor. A voz é empregada na relação com Deus e também nas relações interpessoais com fins de evangelização.

As atividades de evangelização (contextos de pregação e de propagação do evangelho) envolvem relações estabelecidas nos espaços sociais da igreja, em grupos de catequese, escolas dominicais, grupos ou encontros de segmentos 


\begin{tabular}{|c|c|c|c|c|c|c|}
\hline \multicolumn{7}{|c|}{ PARÂMETROS VOCAIS } \\
\hline \multirow{2}{*}{ S } & \multicolumn{2}{|c|}{ LOUDNESS } & \multicolumn{2}{|c|}{ QUALIDADE VOCAL } & \multicolumn{2}{|c|}{ PITCH } \\
\hline & Desenho & Depoimento & Desenho & Depoimento & Desenho & Depoimento \\
\hline 1 & $\begin{array}{l}\text { boca riscos } \\
\text { amarelo notas } \\
\text { musicais, boca } \\
\text { com riscos } \\
\text { marrons }\end{array}$ & $\begin{array}{c}\text { cantando eu } \\
\text { acho que minha } \\
\text { voz é fraca e no } \\
\text { trabalho eu acho } \\
\text { ser boa e forte }\end{array}$ & - & - & - & - \\
\hline 3 & - & - & $\begin{array}{l}\text { palavras boca } \\
\text { riscos retos e } \\
\text { tortos }\end{array}$ & $\begin{array}{l}\text { eu acho minha } \\
\text { voz fluente e } \\
\text { limpa, mas às } \\
\text { vezes oscila }\end{array}$ & - & - \\
\hline 5 & nuvens raios & minha voz é forte & - & $\begin{array}{c}\text { tem possibilidade } \\
\text { de melhora }\end{array}$ & - & - \\
\hline 6 & - & - & bolas coloridas & $\begin{array}{c}\text { acho minha voz } \\
\text { redonda }\end{array}$ & - & - \\
\hline 8 & $\begin{array}{l}\text { Rabiscos azul } \\
\text { forte e fraco, } \\
\text { dentro de forma } \\
\text { geométrica }\end{array}$ & $\begin{array}{c}\text { a cor azul forte } \\
\text { quer dizer que } \\
\text { ela é forte e o } \\
\text { azul fraco porque } \\
\text { ela também é } \\
\text { fraca }\end{array}$ & - & - & - & $\begin{array}{c}\text { às vezes alcanço } \\
\text { um soprano e às } \\
\text { vezes um } \\
\text { contralto (...) } \\
\text { dou uma } \\
\text { desafinadinha }\end{array}$ \\
\hline
\end{tabular}

Figura 8 - Distribuição dos resultados na categoria Parâmetros Vocais

específicos como jovens, casais, senhoras, reuniões, cultos, missas, celebrações e cursos. Nos espaços comunitários e junto à sociedade, a evangelização pode ocorrer em contextos cotidianos e informais, bem como em visitas domiciliares ou visitas a pessoas que se encontram em hospitais ou institucionalizadas, como em educandários, asilos, presídios e outros). As práticas de evangelização se são, ainda, por meio de processos midiáticos (difusão musical de meios como CDs, DVDs e de programas de rádio e de televisão). As diversas condições mencionadas nas práticas de evangelização são abordadas na literatura fonoaudiológica 2-7,25 que considera que, para cada contexto, ambiente, situação, meio e tipo de relação comunicativa/interativa implicada nas atividades de evangelização, há necessidades de uso e qualidade vocal para a fala e o canto que implicam em demandas específicas de para um trabalho de assessoria fonoaudiológica.

Entende-se, portanto, que um trabalho fonoaudiológico de assessoria a integrantes de grupo de louvor, com foco em expressividade da voz falada e cantada, precisa levar em conta a valoração e a importância que a voz assume, para eles, nos usos em atividades e práticas com fins de evangelização - onde se exprime a relação entre voz e espiritualidade/religiosidade.

O uso da voz na relação com Deus, evidenciado na Figura 3, é um dado que merece destaque, uma vez que se trata de uma função e prática de uso que não é mencionada em estudos fonoaudiológicos anteriores com religiosos ${ }^{2-7,25}$.
Na relação com Deus, a voz falada e cantada é valorizada e empregada pelos sujeitos da pesquisa principalmente com os intuitos de louvor/adoração e de invocação; ela é apontada como um dos meios pelos quais expressam seus sentimentos e emoções e fazem agradecimentos e pedidos. Vale destacar a existência de diversas passagens bíblicas que poderiam ajudar a compreender a importância atribuída ao uso da voz, nas práticas religiosas, tais como: "Com júbilo nos lábios a minha boca te louva" - Salmos 63:5b; "Louvarei ao Senhor durante a minha vida; cantarei louvores ao meu Deus, enquanto eu viver" - Salmos 146:2; "Nos seus lábios estejam os altos louvores a Deus" - Salmos 149:6a.

Estudos anteriores ${ }^{25}$ mostraram relações entre crença religiosa e condições de saúde e uso da voz, afirmando a importância de se evidenciar as valorações, sentidos, representações e significações subjetivas, sociais e culturais que influenciam e determinam a saúde vocal de diversos segmentos e categorias profissionais. O emprego da voz na comunicação e relação com Deus é, portanto, um dos aspectos de religiosidade identificados nas representações, saberes e práticas relacionadas aos usos e funções da voz de cantores de grupos de louvor que aponta para relações entre voz e cultura no âmbito da Fonoaudiologia.

A Figura 7 mostra que a maioria dos sujeitos apresenta cuidados com a voz/saúde vocal. Dentre os cuidados mencionados, nota-se a prevalência dos aspectos ligados à religiosidade (especialmente a oração) mencionados por sete sujeitos afirmando, 
mais uma vez, a relação entre saúde e religiosidade apontada na literatura ${ }^{11-15,25,35}$. Concomitantemente às orações os sujeitos demonstraram realizar cuidados que indicam uma concepção de saúde vocal integrada à de saúde geral, em conformidade com os achados de pesquisas anteriores realizadas com religiosos e cantores de grupos de louvor ${ }^{4-6,25}$. Notase que a maioria dos cuidados mencionados está relacionada às mudanças de temperatura, à alimentação, aos abusos vocais e à prática de exercícios vocais; aspectos integrantes das orientações, princípios e noções abordados na literatura sobre higiene vocal, porém insuficientes para a promoção da saúde vocal ${ }^{9,10}$, o que leva a pensar na necessidade de ações fonoaudiológicas junto a estes sujeitos, com foco na promoção da saúde vocal ${ }^{9}$.

As Figuras 3, 5 e 7 evidenciam que as representações, saberes e práticas de cantores de grupo de louvor relacionadas ao uso da voz e aos cuidados de saúde vocal se mostraram impregnadas de aspectos de religiosidade, confirmando que a religiosidade, enquanto parte integrante da cultura, deve ser considerada nos processos educativos participatórios para a promoção da saúde 11-25,33.

A relação entre voz, saúde e espiritualidade/religiosidade é importante e não pode ser negligenciada pelos fonoaudiólogos que se propõem a trabalhar junto a cantores evangélicos.

Por fim, a Figura 8 demonstra que os sujeitos expressam, por desenhos e depoimentos ${ }^{26-30}$, as suas percepções correspondentes, principalmente, por dois parâmetros vocais: loudness e qualidade vocal, sendo que os demais parâmetros não puderam ser expressos ou passaram despercebidos. Os parâmetros de loudness e qualidade vocal estão dentre os que tiveram maior ocorrência também em outros estudos ${ }^{29,34}$ que empregaram desenhos e depoimentos e que, no entanto, obtiveram outros parâmetros percebidos e identificados.

A habilidade de perceber as características e variações dos parâmetros vocais é importante em pessoas que usam a voz profissionalmente especialmente cantores, já que possibilita os ajustes vocais, a identificação precoce de alterações vocais e a procura da assessoria ou atendimento especializado.

Os resultados mostram que as percepções sobre a própria voz se mostraram insuficientes para a promoção da saúde vocal. O desenvolvimento da percepção e exploração da própria voz, a partir dos diversos parâmetros vocais, se faz relevante e este poderia ser um aspecto a ser explorado e desenvolvido a partir de propostas fonoaudiológicas direcionadas aos integrantes deste grupo de louvor.

\section{CONCLUSÃO}

Os cantores de grupo de louvor valorizam a voz falada e cantada em suas vidas, sendo o seu uso e importância especialmente reconhecidos para se relacionarem com Deus e para realizarem as práticas de evangelização. Quanto às práticas de cuidados com a voz e com a saúde geral se fazem presentes, prioritariamente, as crenças e as orações, sendo que os demais cuidados que realizam se mostraram insuficientes para a promoção da saúde vocal.

Os aspectos de religiosidade presentes nas representações, saberes e práticas dos cantores deste grupo de louvor se mostraram, portanto, relacionados aos usos e cuidados com a voz.

\begin{abstract}
Purpose: to identify aspects of religiousness in the knowledge and practices related to the use of voice and vocal health care in participants of Worship Groups. Methods: qualitative research involving data extracted from drawings and written statements about voice, open questionnaire and focal group, placed into categories based on the content analysis/thematic analysis. Results: submitted according to the following categories and attributes: socio-cultural (relation to people and God), essential component, evangelization, professional, vocal health and vocal parameters. Conclusion: the research showed that subjects recognize the value and importance of voice, especially in order to communicate with God and for evangelization practices; in addition to the prevalence of religious believes and praying among the practices of care related to general and vocal health. The research showed needs, knowledge and practices concerning the use of voice and vocal health and affirms the relationship between spirituality/religiousness, showing that this relation is important and cannot be neglected by speech and language therapists who intend to work with the promotion of vocal health among gospel singers.
\end{abstract}

KEYWORDS: Voice; Religion; Health Promotion; Culture 


\section{REFERÊNCIAS}

1. Behlau M. Vozes preferidas: considerações sobre as opções vocais nas profissões. Fono Atual. 2001; 4(16):10-4.

2. Viola IC. A voz dos religiosos. In: Ferreira LP, Oliveira SMRP. Voz profissional: produção científica da fonoaudiologia brasileira. São Paulo: Roca; 2004. p.99-101.

3. Viola IC. A voz dos religiosos. In: Ferreira LP, Oliveira SMRP. Voz profissional II: produção científica da fonoaudiologia brasileira. [CD-ROM]. São Paulo: Comitê de Voz da Sociedade Brasileira de Fonoaudiologia; 2005.

4. Faria DM. Comportamento vocal e características do ambiente em cantores de grupo de louvor. [CD-Rom] Rev Soc Bras Fonoaudiol. Suplemento Especial. Santos; 2005.

5. Faria DM, Silva MAA, Guimarães MAV. Conhecimento sobre saúde vocal e freqüência de hábitos em cantores de grupos de louvor. [CD-Rom] Rev Soc Bras Fonoaudiol. Suplemento Especial. Foz do Iguaçu; 2004-a.

6. Faria DM, Silva MAA, Guimarães MAV. Queixa em relação à voz cantada de participantes de grupo de louvor de Igrejas Cristãs. [CD-Rom] Rev Soc Bras Fonoaudiol. Suplemento Especial. Foz do Iguaçu; 2004-b.

7. Leite GCA, Assumpção R, Campiotto AR, Silva MAA. O canto nas igrejas: o estudo do uso vocal dos coralistas e não coralistas. Dist Comun. 2004; 16(2):229-39.

8. Costa PJBM, Ferreira KL, Camargo ZA, Pinho SMR. Extensão vocal de cantores de coros evangélicos amadores. Rev CEFAC. 2006; 8(1):96-106.

9. Penteado RZ, Chun, RYS, Silva RC. Do "higienismo" às ações promotoras de saúde: a trajetória em saúde vocal. Dist Comun. 2004; 17(1):9-17.

10. Penteado RZ, Maróstica AF, Dias JC, Soares MA, Oliveria NB, Teixeira V, Tonon VA. Saúde vocal: pensando a ação educativa nos grupos de vivência de voz. Saúde em Revista. 2005; 7(16):55-61.

11. White G. Talking about spirituality in health care practice. Health Social Care Commun. 2007; 15(6):606-8.

12. Büssing $A$, Ostermann $T$, Matthiessen PF. Role of religion and spirituality in medical patients: confirmatory results with the SpREUK questionnaire. Health Qual Life Outcomes. 2005; 3:10.

13. Chavez AC, Backett-Milburn K, Parry O, Platt S. Understanding and researching wellbeing: its usage in different disciplines and potential for health research and health promotion. Health Educ J. 2005; 64(1):70-87.
14. Fleck MPA, Borges ZN, Bolognesi G, Rocha NS. Desenvolvimento do WHOQOL, módulo espiritualidade, religiosidade e crenças pessoais. Rev Saúde Pública. 2003; 37(4):446-55.

15. Hawks SR, Smith T, Thomas HG, Christley HS, Meinzer N, Pyne A. The forgotten dimensions in health education research. Health Educ Res. 2008; 23(2):319-24.

16. Raeburn J, Akerman $M$, Chuengsatiansup K, Mejia F, Oladepo $O$. Community capacity building and health promotion in a globalized world. Health Promot Int. 2006; 21(1):84-90.

17. Peterson NA, Hughey J. Social cohesion and intrapersonal empowerment: gender as moderator. Health Educ Res. 2004; 19(5):533-42.

18. Freudenberg N. Community capacity for environmental health promotion: determinants and implications for practice. Health Educ Behav. 2004; 31(4):472-90.

19. Ritchie D, Parry O, Gnich W, Platt S. Issues of participation, ownership and empowerment in a community development programme: tackling smoking in a low-income area in Scotland. Health Promot Int. 2004; 19(1):51-9.

20. Bandesha G, Litva A. Perceptions of community participation and health gain in a community project for the South Asian population: a qualitative study. J Public Health Med. 2005; 27(3):241-5.

21. Heenan D. A partnership approach to health promotion: a case study from Northern Ireland. Health Promot Int. 2004; 19(4):105-13.

22. Wallerstein N. Empowerment to reduce health disparities. Scand J Public Health Suppl. 2002; 30(suppl59):72-7.

23. Willians L, Labonte RO, O'Brien M. Empowering social action through narratives of identity and culture. Health Promot Int. 2003; 18(1):33-40.

24. Wilson N, Minkler M, Dasho S, Wallerstein N, Martin A. Getting to social action: The youth empowerment strategies (YES!) Project. Health Promot Pract. 2006; [epub ahead of print]

25. Penteado RZ, Honorato FG, Nascimento JS. Mulher pastora: questões de gênero e condições de uso da voz no meio religioso. Rev Dist Comun. 2006; 18(3):345-53.

26. Lev-Wiesel R, Shabat A, Tsur A. Stuttering as reflected in adults' self-figure drawings. J Dev Phys Disabil. 2005; 17(1):85-93.

27. Araújo CC, Lacerda C. Linguagem e desenho uma parceria promissora na clínica fonoaudiológica. Temas Desenvolv. 2002; 11(65):10-9. 
28. Driessnack M. Children's drawing as facilitators of communication: a meta-analysis. J Pediatric Nursing. 2005; 20(6):415-23.

29. Pereira PFA, Penteado RZ. Desenhos e depoimentos: recursos para investigação da percepção e do conhecimento vocal. Rev CEFAC. 2007; 9(3):383-96.

30. Luchesi KF, Reilly L. O papel do desenho na clínica fonoaudiológica: profissionais falam de sua prática. Rev Dist Comun. 2007; 19(1):51-61.

31. Penteado RZ, Gonçalves CG, Silvério KCA, Rossi D, Libardi A, Pichirilli TG. Grupos focais: possibilidades e aplicações para as pesquisas e práticas fonoaudiológicas. Rev Bras Fonoaudiol. 2006; 11(2):124-8.

32. Chun RYS, MadureiraS. A qualidade e a dinâmica de voz. Rev Dist Comun. 2004; 15(2):383-92.

33. Panzini RG, Rocha NS, Bandeira DR, Fleck MPA. Qualidade de vida e espiritualidade. Rev Psiq Clín. 2007; 34(1):105-11.

34. Chun RYS, Servilha EAM, Santos LMA, Sanches $\mathrm{MH}$. Promoção da saúde: o conhecimento do aluno de jornalismo sobre a sua voz. Rev Dist Comun. 2007; 19(1):73-80.

RECEBIDO EM: 24/09/2007

ACEITO EM: 14/05/2008

Endereço para correspondência:

Av 41, 209 ap. 62

Rio Claro - SP

CEP: $13501-190$

Tel: (19) 3534-6144

E-mail: rzpenteado@unimep.br 